\title{
What is the role of the consultant in the community?
}

\author{
ANDREw Sims, Professor of Psychiatry, St James's University Hospital, \\ Leeds
}

What follows is concerned with the role of the consultant. To avoid stereotyping of gender or race, this consultant will henceforward be referred to as she and should be considered as of minority ethnic origin.

It is no coincidence that an improvement in the quality of life of the mentally ill has occurred at the same time as the development of psychiatry as a specialty within medicine. There has been a close association between improvement of conditions for those with mental illness and increased sophistication of psychiatry, but the paradox at present is that some well-intentioned actions aimed to help the mentally ill may in fact reverse this process and set back developments in patient care. One is reminded of Edmund Burke: "It is a general popular error to imagine the loudest complainers for the public to be the most anxious for its welfare". In attempting to provide excellence of treatment in the community, it is important to combine what is good in both old and new styles of care.

The starting point for the psychiatrist is to help her patients get better, or at least maximise their capacity for coping with the everyday demands made upon them. With psychotic or dementing illnesses, unlike physical disease, the consultant is sometimes the only advocate for her patient. Essentially the doctor is concerned with an individual patient. She aims to produce the best possible service but has in mind specific individuals who will use it. Managers necessarily have slightly different goals; they put the service first and individuals second. As doctors we need to see things from the patient's point of view: What is in his best interest? What does he actually want? How does he interpret the behaviour of the health care professionals?

In other areas of medicine health care is given according to demand but this is not appropriate in psychiatry. We know, for instance, of many people suffering from chronic schizophrenia living in utter degradation and yet never asking for help. On the other hand, a person with a chronic neurotic disorder may make constant and excessive demands for health care but these may be quite inappropriate, and should result in an offer of a different kind of therapy than that demanded by the patient. So doctors treat patients; the word patient refers to suffering, and whatever the cause, treatment aims to alleviate pain.

The move out of vast forbidding institutions into the community over the last couple of decades has produced considerable benefits for patients past and future, and indicating that there are problems should not detract from that. 'Care in the community', when it really is care and is genuinely taking place within the community, is one of the most important benefits of recent trends for the mentally ill.

Unfortunately, sometimes only neglect in the community as portrayed by Weller (1985) in his account of chronic psychotic patients discharged from a London mental hospital, occurs. Is it really 'in the community' when discharged patients live a ghettolike existence in big old houses with inadequate heat and furniture, without proper care and supervision and feared by their healthy neighbours? There is also the danger of day care on the cheap, perhaps unskilled personnel looking after chronically disabled previous patients in poor buildings with inadequate resources. It is unacceptable, even when housing and general practice medical care is satisfactory, for people suffering from chronic schizophrenia to be looked after in the community in such a way that they are physically healthy, but bored and lonely. These are situations where the consultant, as advocate, should either be making the case to retain the mental hospital beds and resources or alternatively ensuring that really adequate provision is made in the community. These patients are unlikely to make demands for improved conditions themselves, and may be most unwilling patients.

'Care in the community', then, has become one of the most popular clichés of this decade. It is implied that the community, and treatment in the community, is automatically better than treatment in hospital. This is clearly nonsense. There should be more emphasis on discriminating between those aspects of treatment which benefit from being in the community and those which require hospital treatment. After all the mentally ill were to be found "in the community" for centuries, and were totally neglected there, until the humane inventiveness of the Enlightenment and the reforming energy of the Victorians resulted in asylum where they could be looked after in relative tranquillity and protected from exploitation by the unscrupulous. 


\section{Training of the consultant psychiatrist for community oriented psychiatric care}

If the psychiatrist is to work partly or substantially in the community then her training needs to reflect this. The psychiatrist of the future will need to know more about certain aspects of management and to have a different range of skills from her predecessor. In moving some of training from its secure base in the hospital, there is a danger of de-skilling in the diagnosis and theoretical aspects of psychiatry, difficulty in keeping in touch with one's peer group and forming a large enough core for teaching, a possible loss of necessary teaching facilities, and difficulty in keeping in close contact with the educational supervisor or consultant in the community.

Connolly (1989) has listed aspects of training needed for community-oriented psychiatric care. An important part of training for the psychiatrist working in the community will be acquiring knowledge and learning skills in management. For example, a consultant in mental handicap moving from the institution into the community will need to become the pivot for developing services for a population of approximately 200,000 and providing appropriate mental handicap services for different types of disability.

\section{The multidisciplinary team}

Most doctors, at least for a part of their professional time, work in multidisciplinary teams. This is true for the surgeon, for the general practitioner and also for the psychiatrist; generally, working in a team is both more effective in helping patients and more congenial to those who work.

When the doctor is working in the community she will find herself associated with two different types of team. These could be designated the clinical team, where the team is organised to help specifically with the psychiatric management of individual patients, and other types of team. For instance, the consultant in the community may find herself involved with planning a day centre instigated by a Charity for the elderly or in taking part in a social services case conference. The consultant role is radically different in these two types of team. In the clinical team the consultant is necessarily the leader, as she carries clinical responsibility, whereas in these other teams she is called in as a specialist and will not usually be a leader.

\section{The consultant as leader of the team}

What follows is specifically concerned with the clinical team, that is where patients have been referred to a doctor, or a team in which a doctor works, and the doctor therefore accepts clinical responsibility. Bennet (1988) stated: "Psychiatrists cannot assume that they will automatically be in charge of the teams in which they work, and, though this prospect may alarm some, it has a good historical background". He then pointed out that the sister or charge nurse has over a very long time managed general wards. This is undoubtedly true and the junior doctor needs to bear this in mind! However, the sister or charge nurse is answerable to the consultant for the care of individual patients, and the consultant carries a different responsibility as leader of the clinical team.

For work in the community, although other members of the team should take responsibility, for example as the manager of a day centre, when the multidisciplinary team is meeting in its clinical capacity, the consultant should, with rare exceptions, be the leader of the team. This is inexorably related to role and clinical responsibility, and should not be dependent upon personality or behavioural style; many management courses for other professions include assertiveness training! The corollary, of course, is that she who does not wish to assume this responsibility should not aspire to consultancy.

Here are some of the reasons why the consultant will need to assume leadership:

(a) Her very broad and comprehensive training, and even initial selection for training, in general best fits her for this role;

(b) other professional disciplines, other medical referrers, and patients will assume and prefer her to be in this role;

(c) she is paid for taking this responsibility;

(d) legally she will be considered to be the responsible medical officer;

(e) her specialist training in the use of diagnosis with precision and economy, and in the broad aspects of treatment methods equip her for this role;

(f) she is most likely to be in the best position for innovation in treatment methods, service, and advocacy for the individual patient;

(g) in practice she is very often the longest serving person with that individual patient. This is especially so because of the habit of promotion out of clinical work for other professionals;

(h) if the consultant is not in this role, usually anarchy ensues rather than an alternative form of clinical care.

Of course, leadership style is extremely important. This should not be authoritarian nor dictatorial, neither should it be negligent or laissez-faire. It should be democratic, and encourage development of leadership skills in other members of the treatment team in particular areas of the work. Members of the team should have freedom to organise their own work in the most effective way possible. 
In order for a multidisciplinary team to work, there must be someone whose job it is to hold the team together and also who has the power to do this. Where, through the consultants not filling this role, there is a vacuum some other member of the team will either be sucked into this role, or blow themselves into it. However, usually they will not, or are not able, to fill all parts of the leadership role in the team. Some other mental health professionals are extremely good at providing a service, but not so good at assessing requests for treatment, and there is, therefore, a tendency for them to drift into areas where they have not been specifically trained, and to deal with people who cannot really benefit from their expertise. For example, the most effective use of a community psychiatric nursing service lies in answerability to a consultant psychiatrist with referral of patients to that consultant, although working with general practitioners.

A patient, who usually communicates with her therapists by letter, wrote the following: “... Can I ask the questions? Should I come off the sick? Should I go to the day centre? Will I ever be like everyone else? Will my body work right? What's wrong with me? Why do I feel swollen? The anguish feeling, what is it? Why am I in two minds? I keep feeling tearful, irritable, why? I seem to be getting softer, can you tell me what I should do?". It is very uncomfortable for a consultant to be bombarded with a battery like that, but that is the nature of the job. It is very difficult to find the narrow path between reinforcing her neurotic importunity on the one hand, and proving to her yet again that everyone rejects her on the other.

What is the role of the consultant psychiatrist in the clinical team in the community? Although the setting has changed, the spacious lawns of the mental hospital have been replaced by the cramped streets of the inner city, the role has not in fact changed. The consultant continues to have the two duties that she has had for the last $\mathbf{4 0}$ years since the inception of the National Health Service. She is the consultant or specialist giving advice on patient management and provision of services to general practitioners, social workers, managers and so on, and she is the leader of a multiprofessional team responsible for providing care for individual patients who are in the community.

\section{References}

BENNET, G. (1988) What should psychiatry be doing in the 1990's. British Medical Journal, 296, 274-275.

ConNolly, J. (1989) Community-oriented psychiatric care: Some ideas on training. Psychiatric Bulletin of the Royal College of Psychiatrists, 13, 26-27.

WELLER, M. P. I. (1985) Friern Hospital: Where have all the patients gone? Lancet, 1, 569-571.

\section{Locally based community care}

\section{A personal view}

\section{KeITH RICHARDSON, formerly Campaigns Organiser, Northern MIND}

A cynic might regard the plethora of reports on community care as a study in how to create the impression of activity while doing nothing. Demands or suggestions for action are easily deflected by holding up the spectre of a forthcoming inquiry - for example the Griffiths' report on community care. Only six months after its launch, one could be excused for thinking that Sir Roy's report never happened. But it would be short-sighted to view Griffiths as a non-event. It embodies a workable framework for implementing community care, emphasises the importance of individual choice and demonstrates the foolishness of relying on those above to wave magic wands and produce instant national solutions. Community care is about localising services and must evolve locally.

Current approaches to transferring care from institutions to the community result in levels of cost and complexity which make a small scale approach difficult because the proposed solutions are far from community based. A solution that is truly local can be implemented step by step, area by area, without the need for an all or nothing transition. This is what has been found at Northern MIND with the model developed for a local adult mental health network. 